\title{
Association of HbA1c with Dyslipidemia in type 2 diabetic patients
}

\author{
Ravirala Tagore ${ }^{1}$, Ayesha Jabeen ${ }^{2}$, V L Asha Latha ${ }^{2 *}$, Amthul Rahman², SLV Sankeerthi ${ }^{2}$, K Chetan Kumar $^{3}$ \\ ${ }^{1}$ Professor \& HOD, ${ }^{2}$ Assistant Professor, ${ }^{3}$ Tutor, Department Of Biochemistry, Mahavir Institute Of Medical Sciences(MIMS), Vikarabad \\ District, Telangana, INDIA. \\ Email: vlashalatha@gmail.com
}

Abstract Background: Dyslipidemia is a very common finding in patients with type 2 Diabetes Mellitus (DM) which strongly increases risk for the development of cardiovascular diseases. The aim of this study was to determine the pattern of dyslipidemia and to establish the correlation between glycated haemoglobin (HbA1c) and lipid profile in type 2 DM. Methods: The sera of 162 patients (100 males and 62 females) with type 2 DM were analyzed for HbA1c, fasting blood sugar (FBS), postprandial blood sugar (PPBS), total cholesterol (TC), triglycerides (TGs), high-density lipoprotein (HDL) and low-density lipoprotein (LDL) levels. We divided the subjects based on their glycemic index into three groups; HbA1c< $6 \%$ (good), HbA1c 6\%-9\% (poor) and $\mathrm{HbA1c}>9 \%$ as worse glycemic control. A correlation between the variables was done by pearson's correlation analysis. Results: A significant positive correlation was found between HbA1c with FBS $(\mathrm{r}=0.504)$, PPBS $(\mathrm{r}=0.628)$, TC $(\mathrm{r}=0.557)$, TGs $(\mathrm{r}=0.517)$, LDL $(\mathrm{r}=0.592)$ and significant negative correlation with HDL $(\mathrm{r}=-0.449)$. The low mean values of HbA1c, FBS, PPBS, TC, TGs and LDL and high mean values of HDL were observed in patients with good glycemic control than those with poor and worse glycemic control. Our study shows very little variations of HbA1c, FBS, PPBS and lipid profile parameters in male and female diabetic patients. Conclusion: Our study shows that HbAlc can be utilized as a potential biomarker for predicting dyslipidemia in type 2 diabetic patients in addition to glycemic control.

Key Words: Diabetes Mellitus, Cardiovascular disease, Dyslipidemia, Glycated hemoglobin, Lipid profile.

*Address for Correspondence:

Dr V.L. Asha Latha, Assistant Professor, Department. OF Biochemistry, Mahavir Institute OF Medical Sciences (Mims), Vikarabad District, Telangana, INDIA.

Email: vlashalatha@gmail.com

Received Date: 21/11/2019 Revised Date: 05/01/2020 Accepted Date: 29/01/2020

DOI: https://doi.org/10.26611/10021421

This work is licensed under a Creative Commons Attribution-NonCommercial 4.0 International License. (cc)) BY-NC

\begin{tabular}{|l|l|}
\hline \multicolumn{2}{|c|}{ Access this article online } \\
\hline Quick Response Code: & Website: \\
\hline & www.medpulse.in \\
& \\
& \\
\hline
\end{tabular}

\section{INTRODUCTION}

Type 2 Diabetes mellitus (DM) is a common metabolic disorder which is characterized by impaired pancreatic $\beta$ cell function leading to insulin resistance, increased production and decreased utilization of glucose ${ }^{1}$. DM is expeditious growing health problem in the world wide with the development of cardio vascular disease (CVD) associated with atherogenic dyslipidemia and other chronic complications leading to significant morbidity and mortality ${ }^{2}$. Dyslipidemia in type 2 DM patients is characterized by elevated triglycerides (TGs), low density lipoproteins (LDL) and reduced high-density lipoprotein (HDL) and increased circulating insulin concentration ${ }^{3}$. The higher prevalence of lipid abnormalities in DM has been attributed to insulin resistance or deficiency that affects key enzymes and pathways in lipid metabolism. The conditions like hyperglycemia, dyslipidemia and CVD are inter-related well with each other in type $2 \mathrm{DM}^{4}$ and recently, elevated glycated haemoglobin ( $\mathrm{HbA1c}$ ) has been regarded as an independent risk factor for CVD and stroke in patients with or without DM. HbAlc is routinely utilized as standard biomarker for measuring glycemic control. In accordance with its function as an indicator for the mean blood glucose level, $\mathrm{HbAlc}$ predicts the risk of diabetic 
complications and also as valuable biomarker for prognosticating serum lipid status in DM. ${ }^{5}$ Very few investigators have reported the significant correlations between $\mathrm{HbA} 1 \mathrm{c}$ and lipid profile ${ }^{6,7}$ and 8 and suggested the importance of $\mathrm{HbA} 1 \mathrm{c}$ in predicting the dyslipidemia in DM. Thus, we aimed to study and assess the relationship between HbA1c levels and serum lipid profile as well as to evaluate the importance of HbAlc as an indicator of dyslipidemia in patients with Type 2 DM. Hence, the present study was undertaken to observe the correlation of HbAlc with lipid profile for the early determination of dyslipidemia in type 2 DM patients.

\section{MATERIALS AND METHODS}

This study was a cross sectional study conducted in the Department of Biochemistry at Mahavir Institute of Medical Sciences (MIMS), Vikarabad, Telangana. A total of 162 (100 males, 62 females) consecutive patients attending General Medicine OPD either diagnosed as type 2 diabetic as per American Diabetes Association guidelines $2013^{9}$ or already taking treatment for type 2 diabetes from October 2019 to January 2020 were enrolled in the study. The type $2 \mathrm{DM}$ patients with irrespective duration of disease, with good treatment, in regular followup and those willing to participate were included in this study. An exclusion criterion was patients taking statins for dyslipidemia, with gestational diabetes and diabetic pregnant women. The study was approved by the institutional ethical committee and informed consent was taken from all the patients. Venous blood samples were collected from all the patients after 8hrs of fasting and serum was separated by centrifugation at 3000rpm for
$15 \mathrm{~min}$. The serum was used for analyzing fasting blood sugar (FBS), Post prandial blood sugar (PPBS), total cholesterol (TC), triglycerides (TGs) and high-density lipoprotein cholesterol (HDL) using the semi automated clinical chemistry analyzer (ERBA EM-200 analyzer, Germany). The level of LDL cholesterol was determined using the Friedewald formula: LDL $=$ (cholesterol-TG)/ $(2.2 \mathrm{HDL}){ }^{10}$. For a serum lipid reference level, National Cholesterol Education Programme (NCEP) Adult Treatment Panel III (ATP III) guideline was referred. According to NCEP-ATPIII guideline, hypercholesterolemia is defined as TC>200 mg/dl, high LDL-C $>100 \mathrm{mg} / \mathrm{dl}$, hypertriglyceridemia as TAG $>150$ $\mathrm{mg} / \mathrm{dl}$ and low HDL-C $<40 \mathrm{mg} / \mathrm{dl}$. Dyslipidemia was defined by presence of one or more than one abnormal serum lipid concentration ${ }^{11}$. All the patients were investigated for $\mathrm{HbAlc}$ using an $\mathrm{Hb}$ Vario analyzer (Transasia Biomedicals Pvt Ltd, USA). The impact of glycemic control on various parameters was evaluated into 3 categories on the basis of HbAlc levels: $\mathrm{HbAlc}<6 \%$ (good glycemic control), HbAlc 6-9\% (poor glycemic control) and $\mathrm{HbA} 1 \mathrm{c}>9 \%$ (worse glycemic control). The selection of these cut-off values of HbA1c was based on earlier studies ${ }^{12}$. The data was evaluated by SPSS version 11.0. Independent sample t-test (2-tailed) was used to compare means of different parameters. Pearson correlation analysis was performed to examine the correlations between $\mathrm{HbA1c}$, FBS, PPBS and lipid profile parameters. All values are expressed as mean \pm standard deviation (SD) and $\mathrm{P}$-value $<0.05$ was considered as statistically significant. The estimation of HbA1c was given as percentage of total haemoglobin and values of all other parameters were given in $\mathrm{mg} / \mathrm{dL}$.

\section{RESULTS}

\begin{tabular}{|c|c|}
\hline Parameter & Mean \pm SD \\
\hline Age (years) & $49.16 \pm 13.48$ \\
\hline HbA1c (\%) & $8.37 \pm 2.61$ \\
\hline $\mathrm{FBG}(\mathrm{mg} / \mathrm{dl})$ & $119.83 \pm 20.36$ \\
\hline PPBS (mg/dl) & $165.24 \pm 31.38$ \\
\hline $\mathrm{TC}(\mathrm{mg} / \mathrm{dl})$ & $180.25 \pm 53.45$ \\
\hline TGs (mg/dl) & $198.0 \pm 90.50$ \\
\hline $\mathrm{HDL}$ (mg/dl) & $29.53 \pm 7.72$ \\
\hline $\mathrm{LDL}(\mathrm{mg} / \mathrm{dl})$ & $150.72 \pm 55.71$ \\
\hline $\operatorname{VLDL}(\mathrm{mg} / \mathrm{dl})$ & $39.61 \pm 18.10$ \\
\hline
\end{tabular}

HbA1c: Hemoglobin A1c, TC: Total cholesterol, TGs: Triglycerides, HDL: High-density lipoprotein, LDL: Low-density lipoprotein, VLDL: Very low-density lipoprotein, FBS: Fasting blood sugar, PPBS: Post-prandial blood suga, SD: Standard deviation

Table 2: HbA1c and Lipid Profile parameters of Male and Female Type 2 Diabetic patients

\begin{tabular}{ccc}
\hline Parameter & Male $(\mathrm{n}=100)$ & Female $(\mathrm{n}=62)$ \\
\hline Age (years) & $49.88 \pm 12.72$ & $47.93 \pm 14.49$ \\
HbA1c (\%) & $8.34 \pm 2.49$ & $8.48 \pm 2.81$ \\
FBG $(\mathrm{mg} / \mathrm{dl})$ & $120.74 \pm 19.23$ & $118.55 \pm 22.1$ \\
\hline
\end{tabular}




\begin{tabular}{ccc}
\hline PPBS $(\mathrm{mg} / \mathrm{dl})$ & $165.88 \pm 29.0$ & $165.2 \pm 35.5$ \\
$\mathrm{TC}(\mathrm{mg} / \mathrm{dl})$ & $176.27 \pm 47.8$ & $186.3 \pm 61.8$ \\
$\mathrm{TGs}(\mathrm{mg} / \mathrm{dl})$ & $195.01 \pm 89.02$ & $204.02 \pm 93.6$ \\
$\mathrm{HDL}(\mathrm{mg} / \mathrm{dl})$ & $29.50 \pm 7.62$ & $29.06 \pm 7.46$ \\
$\mathrm{LDL}(\mathrm{mg} / \mathrm{dl})$ & $146.76 \pm 50.70$ & $157.24 \pm 40.8$ \\
$\mathrm{VLDL}(\mathrm{mg} / \mathrm{dl})$ & $39.0 \pm 17.80$ & $40.80 \pm 18.73$ \\
\hline
\end{tabular}

HbA1c: Hemoglobin A1c, TC: Total cholesterol, TGs: Triglycerides, HDL: High-density lipoprotein, LDL: Low-density lipoprotein, VLDL: Very low-density lipoprotein, FBS: Fasting blood sugar, PPBS: Post-prandial blood sugar

Table 3. Lipid Profile parameters categorized by Glycemic control

\begin{tabular}{cccc}
\hline Parameter & \multicolumn{3}{c}{ HbA1c } \\
\cline { 2 - 4 } & $<6 \%(n=32)$ & $6-9 \%(n=70)$ & $>9 \%(n=60)$ \\
& Good control & Poor control & Worse control \\
\hline HbA1c (\%) & $5.54 \pm 0.28$ & $7.21 \pm 1.01$ & $11.32 \pm 1.65$ \\
FBG $(\mathrm{mg} / \mathrm{dl})$ & $93.03 \pm 8.15$ & $123.17 \pm 15.16$ & $130.79 \pm 17.68$ \\
PPBS $(\mathrm{mg} / \mathrm{dl})$ & $124.62 \pm 20.67$ & $166.4 \pm 18.91$ & $187.05 \pm 26.1$ \\
TC $(\mathrm{mg} / \mathrm{dl})$ & $150.59 \pm 25.92$ & $163.75 \pm 31.62$ & $216.76 \pm 64.38$ \\
TGs $(\mathrm{mg} / \mathrm{dl})$ & $143.21 \pm 49.67$ & $175.39 \pm 64.29$ & $257.10 \pm 102.24$ \\
HDL $(\mathrm{mg} / \mathrm{dl})$ & $34.53 \pm 8.39$ & $30.06 \pm 6.97$ & $25.85 \pm 6.44$ \\
LDL(mg/dl) & $116.05 \pm 23.10$ & $133.7 \pm 33.58$ & $190.91 \pm 65.25$ \\
VLDL(mg/dl) & $28.64 \pm 9.93$ & $35.1 \pm 12.9$ & $51.42 \pm 20.44$
\end{tabular}

HbA1c:HemoglobinA1c, TC: Total cholesterol, TGs: Triglycerides, HDL: High-density lipoprotein, LDL: Low-density lipoprotein, VLDL: Very low-density lipoprotein, FBS: Fasting blood sugar, PPBS: Post-prandial blood sugar

Table 4: Correlation between HbA1c, FBS and Lipid profile

\begin{tabular}{clccccc}
\hline & & TC & TGs & HDL & LDL & VLDL \\
\hline HbA1c & Pearson Correlation & $0.557^{* * *}$ & 0.517 & $-0.449^{* * *}$ & $0.592^{* * *}$ & -0.012 \\
FBS & Pearson Correlation & $0.276^{* * *}$ & 0.478 & $-0.222^{* * *}$ & $0.296^{* * *}$ & $0.478^{* * *}$ \\
\hline
\end{tabular}

$* * * \mathrm{P}<0.001$. HbA1c: HemoglobinA1c, TC: Total cholesterol, TGs: Triglycerides, HDL: High-density lipoprotein, LDL: Low-density lipoprotein, VLDL: Very low-density lipoprotein, FBS: Fasting blood sugar.

The baseline and biochemical parameters of the total study subjects were shown in Table 1. Table 2 shows genderwise distribution of the study subjects, out of the total 162 subjects, 100 were male and 62 were females. The mean age \pm SD of males and females was $49.88 \pm 12.72$ years (range: $37-63 y e a r s)$ and $47.93 \pm 14.49$ (range: 33-63years), respectively. Our study results showed very little variations in levels of $\mathrm{HbAlc}$, FBS, PPBS and HDL in male and female diabetic patients. The levels of TC, TGs, LDL and VLDL were slightly higher in females than males that were not statistically significant. Therefore, no significant difference was observed in the present study in $\mathrm{HbA} 1 \mathrm{c}$ and lipid profile parameters for gender categorization. To study the utility of HbAlc as a marker of dyslipidemia, we divided subjects into three groups depending upon the levels of HbA1c i.e. $\operatorname{good}(<6 \%)$, poor $(6-9 \%)$ and worse $(>9 \%)$ glycemic control groups (Table 3). The mean \pm SD levels of FBS, PPBS and glycemic index $\mathrm{HbAlc}$ was found to be increased in poor control $(123.1 \pm 15.1 ; 166.4 \pm 18.9$ and $7.21 \pm 1.01$ respectively) and more in worse control $(130.7 \pm 17.6 ; 187.0 \pm 26.1$ and $11.32 \pm 1.65$ respectively) compared to good control $(93.03 \pm 8.15 ; 124.6 \pm 20.6$ and $5.54 \pm 0.28)$ patients. Similarly the mean value of TC, TGs,
LDL and VLDL was found to be lower in patients with good glycemic control than those with poor and worse glycemic control patients. However, the higher mean value of HDL was found in patients with good glycemic control than those with poor and worse glycemic control.

Correlation between HbA1c and FBS, PPBS, TC, TGs, HDL, LDL and VLDL:

Pearson correlation coefficient (r) was calculated to find out the correlation between the FBS, PPBS and HbAlc and various lipid profile parameters. Highly significant correlation was observed between HbA1c, FBS $(r=0.504$; $\mathrm{P}<0.0001)$ and PPBS $(\mathrm{r}=0.628 ; \mathrm{p}<0.0001)$ and also demonstrated direct and significant correlations with TC $(\mathrm{r}=0.557 ; \quad \mathrm{p}<0.0001), \quad$ LDL $\quad(\mathrm{r}=0.592 ; \quad \mathrm{p}<0.001$ respectively). A positive correlation was found between HbAlc and TGs $(r=0.517)$ with no statistical significance. However, a negative correlation was seen between $\mathrm{HbAlc}$ and HDL $(\mathrm{r}=-0.449 ; \mathrm{p}<0.001)$ and mild negative correlation was observed between HbA1c and VLDL ( $\mathrm{r}=-$ 0.012) which is not statistically significant (Table 4). Along with $\mathrm{HbA} 1 \mathrm{c}$ we also performed correlation between FBS and all lipid parameters. We found a significant positive correlation with PPBS $(\mathrm{r}=-0.728 ; \mathrm{p}<0.001) \mathrm{TC}$ 
$(\mathrm{r}=0.276 ; \mathrm{p}<0.001)$, LDL $(\mathrm{r}=-0.296 ; \mathrm{p}<0.001)$ and VLDL $(\mathrm{r}=-0.478 ; \mathrm{p}<0.001)$ and significant negative correlation with $(\mathrm{r}=-0.222 ; \mathrm{p}<0.001)$. A positive correlation was found between FBS and TGs $(r=0.478)$ with no statistical significance (Table 4).

\section{DISCUSSION}

The present study aimed to define the correlation between HbAlc and lipid profile and also to determine the pattern of dyslipidemia in type $2 \mathrm{DM}$ patients. The glycemic parameters (FBS, PPBS and HbAlc) did not differ significantly in type 2 diabetic male and female subjects, where as the slight rise in TC, TGs, LDL and VLDL was found in female diabetic patients in the present study (Table 2). These findings suggest that the pattern of dyslipidemia could vary in male and female diabetic subjects. In both males and females, diabetes shows a markedly increase risk of events, however the diabetic woman is more susceptible to increased cardio vascular mortality. Our finding is in agreement with the previous studies $5,13,14$. Hyperlipidemia in females may be attributed to the effects of sex hormones on body fat distribution, which leads to differences in altered lipoproteins. The Diabetes complications and control trial (DCCT) established HbAlc as the best level of glycemic control ${ }^{15}$. To see the impact of glycemic control on various lipid parameters the diabetic patients are categorized into 3 groups based on the HbAlc levels i.e. good glycemic control ( $\mathrm{HbAl}<6 \%$ ); poor glycemic control (HbA1c 6\%$9 \%$ ) and worst glycemic control (HbAlc $>9 \%)^{6}$ and12. We found a linear and increase in HbAlc, FBS, PPBS, TC, TGs, LDL, VLDL and decreased HDL in the patients with poor and worse glycemic control than in good glycemic control. Thus, HbAlc provides a reliable measure of chronic glycemia and correlates well with the risk of longterm diabetes complications, so that it is currently considered as gold standard test for the assessment and chronic management of diabetes mellitus ${ }^{7}$.In the present study, we observed that $\mathrm{HbA} 1 \mathrm{c}$ has direct and significant correlations with FBS, PPBS, TC, TGs and LDL and inverse correlation with HDL and VLDL. Our findings are concomitant with previous studies 6, 16, 17,18 who also reported a direct and significant correlation between HbA1c with TC, TG and LDL and reverse correlation with HDL. The cause of dyslipidemia in type 2 DM may be due to impaired liver apolipoprotein production which in turn regulates the enzymatic activity of lipoprotein lipase (LPL) and cholesterol ester transport protein ${ }^{19,20}$. Dyslipidemia as a metabolic abnormality is strongly linked with type 2 DM and its prevalence vary, depending on the type and severity of diabetes, glycemic control, nutritional status, age and other factors 21 . In our study, the significant correlations were found between $\mathrm{HbA1c}$, FBS, PPBS and all the lipid profile parameters finds a linear relationship between $\mathrm{HbA} 1 \mathrm{c}$ and dislipidemia which points towards the usefulness of $\mathrm{HbA} 1 \mathrm{c}$ for screening the high risk diabetic patients. This finding supports $\mathrm{HbA} 1 \mathrm{c}$ is better predictor and can be used as a potential biomarker for predicting dyslipidemia in type 2 diabetic patients.

\section{CONCLUSION}

The findings of the present study showed a significant positive correlation between $\mathrm{HbA}$ 1c with FBS, PPBS, TC, TGs, LDL and negative correlation with HDL and VLDL. In the present study, the levels of HbAlc, FBS, PPBS, TGs, LDL, VLDL, and HDL did not differ significantly between male and female diabetic patients. Thus, HbA1c endures the ability of predicting serum lipid profile in both male and female diabetic patients. To conclude, the findings of our study clearly show that HbAlc which is gold standard in the assessment of glycemic control together with its strong correlation with the lipid profile which makes an ideal marker for predicting dyslipidemia in type $2 \mathrm{DM}$.

\section{REFERENCES}

1. Fier BM FM. 'Diabetes Mellitus' in Davidson's Principles and Practice of Medicine, 20 th edition. Churchill Livingstone Elsevier; 2006.

2. Haffner SM: Lipoprotein disorders associated with type 2 diabetes mellitus and insulin resistance: Am J Cardiol. 2002; 90: 55-61.

3. Gadi R, Samaha FF: Dyslipidemia in type 2 diabetes mellitus: Curr Diab Rep. 2007 Jun;7(3): 228-34.

4. JK Baranwal JK, Maskey R, Majhi S, Lamsal M, Bara N: Association between level of HbAlc and lipid profile in T2DM patients attending diabetic OPD at BPKIHS: Health Renaissance. 2015; 13(3):16-23.

5. Mahato RV, Prajwal G, Pramod PR, Prashant R, Khelanand PS, Dipendra RP et al.: Association between glycaemic control and serum lipid profile in type 2 diabetic patients: Glycated haemoglobin as a dual biomarker: Biomedical Research. 2011;22(3):375-80.

6. Ahmad Khan H: Clinical significance of HbAlc as a marker of circulating lipids in male and female type 2 diabetic patients: Acta Diabetol. 2007 Dec; 44(4):193-200.

7. Mahesh Kumar CH, Gayatri M, Arun M: Study of association between FBS, HbAlc level and lipid profile in type 2 diabetes mellitus: MedPulse International Journal of Pathology. Sep 2018; 7(3): 159-163.

8. Lokendra BS, Sangita T: Pattern of Dyslipidemia in Type 2 Diabetic Patients attending Tertiary Care Centre of Nepal: EC Endocrinology and Metabolic Research 2019; 4(9):15-22.

9. Diagnosis and classification of diabetes mellitus: American Diabetes Association. Diabetes care. 2014 Jan; 37(Supplement 1):S81-90.

10. Warnick GR, Knopp RH, Fitzpatrick V, Branson L: Estimating low-density lipoprotein cholesterol by the Friedewald equation is adequate for classifying patients on 
the basis of nationally recommended cutpoints: Clin Chem. 1990 Jan;36(1):15-9.

11. Executive summary of the Third Report of the National Cholesterol Education Program (NCEP) expert panel on detection, evaluation, and treatment of high blood cholesterol in adults (Adult Treatment Panel III). Expert Panel on Detection, Evaluation, and Treatment of high Blood Cholesterol in Adults: JAMA. 2001 May 16;285(19):2486-97.

12. Rosediani M, Azidah AK, Mafauzy M: Correlation between fasting plasma glucose, post prandial glucose and glycated haemoglobin and fructosamine: Med J Malaysia. 2006 Mar;61(1):67-71.

13. Wexler DJ, Grant RW, Meigs JB, Nathan DM, Cagliero E: Sex disparities in treatment of cardiac risk factors in patients with type 2 diabetes: Diabetes Care. 2005 Mar;28:514-20.

14. Sibley SD, Thomas W, de Boer I, Brunzell JD, Steffes MW: Gender and elevated albumin excretion in the Diabetes Control and Complications trial/ Epidemiology of Diabetes Interventions and Complications (DCCT/EDIC) cohort: role of central obesity: Am J Kidney Dis. 2006 Feb; 47(2): 223-32.

15. DCCT Research Group: The absence of a glycemic threshold for the development of long-term complications: the perspective of the diabetes control and complications trial: Diabetes 1996 Oct;45(10):1289-98.

16. Klisic A, Kavaric N, Jovanovic M, Zvrko E, Skerovic $\underline{\mathrm{V}}, \underline{\text { Scepanovic A }}$ et al.: Association between unfavorable lipid profile and glycemic control in patients with type 2 diabetes mellitus: J Res Med Sci. 2017 Nov $28 ; 22: 122$.

17. Ladeia AM, Adan L, Couto-Silva AC, Hiltner A, Guimaraes AC: Lipid profile correlates with glycemic control in young patients with type 1 diabetes mellitus: Prev Cardiol. 2006 Spring ; 9(2):82-8.

18. KP, Kunikullaya UK, Goturu J: Glycosylated Haemoglobin (HbA1c) - A Marker of Circulating Lipids in Type 2 Diabetic Patients: J Clin Diagn Res. 2014 Feb; $8(2): 20-3$

19. Elinasri HA, Ahmed AM: Patterns of lipid changes among type 2 diabetes patients in Suda: Eastern Mediterr Health J. 2008 Mar-Apr; 14(2):314-24.

20. Mooradian AD: Dyslipidemia in type 2 diabetes mellitus: Nat Clin Pract Endocrinol Metab. 2009 Mar;59(3):150-9.

21. Krentz AJ: Lipoprotein abnormalities and their consequences for patients with type 2 diabetes: Diabetes Obes Metab. 2003 Nov;5(1):S19-27.

\section{Source of Support: None Declared Conflict of Interest: None Declared}

Policy for Articles with Open Access:

Authors who publish with MedPulse International Journal of Anesthesiology (Print ISSN:2579-0900) (Online ISSN: 2636-4654) agree to the following terms: Authors retain copyright and grant the journal right of first publication with the work simultaneously licensed under a Creative Commons Attribution License that allows others to share the work with an acknowledgement of the work's authorship and initial publication in this journal.

Authors are permitted and encouraged to post links to their work online (e.g., in institutional repositories or on their website) prior to and during the submission process, as it can lead to productive exchanges, as well as earlier and greater citation of published work. 